\title{
Solvent Extraction of Metal lons from Sulfate Solutions Obtained in Leaching of Spent Ni-MH Batteries
}

\author{
Beata Pospiech, Jerzy Gega \\ Czestochowa University of Technology, Poland
}

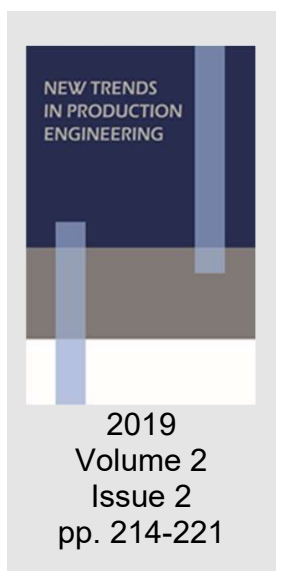

Date of submission to the Editor: 09/2019

Date of acceptance by the Editor: 11/2019

\section{INTRODUCTION}

The nickel metal hydride batteries (Ni-MH) are very popular and often used in the hybrid cars and many electronic equipment because of numerous advantages, such as the high capacity, chemical stability, low toxicity, price and safety (Innocenz et al., 2017).Therefore, all the time the production of this type of batteries increases.

The composition of Ni-MH is quite specific. Nickel hydroxide is used as the cathode and intermetallic compounds (alloy) as the anode. It is worth to mention that rare earth elements (REE) such as lanthanum (La), cerium (Ce), praseodymium $(\mathrm{Pr})$ and neodymium $(\mathrm{Nd})$, are the components of the anode. Moreover, the batteries also contain cobalt, manganese, iron, zinc and aluminum. Potassium hydroxide $(\mathrm{KOH})$ is usually used as the electrolyte (Innocenz et al., 2017).

As can be seen, spent batteries contain many heavy metals and should be collected and recycled in order to recovery of useful components as well as due to ecological reasons.

In the recent years, the hydrometallurgical processes are very often used for the batteries recycling (Zhang et al., 2005; Bertuol et al. 2009; Li et al., 2009; Rodrigues \& Mansur, 2010; Meshram et al., 2016, 2017; Pospiech, 2013; Chagnes \& Pospiech, 2013). This treatment involves mainly the leaching of metals from the spent batteries, separation of metal ions from leach liquor and extraction or precipitation of metals. It is worth to remember that the mechanical pretreatments of the spent batteries is carried out before the leaching.

We can find many works concerning chemical leaching of metals from $\mathrm{Ni}-\mathrm{MH}$. For instance, Fernandes et al. (2013) studied the leaching of the spent batteries using $12 \mathrm{M}$ hydrochloric acid at $40^{\circ} \mathrm{C}$. Bertuol et al. (2009) recovered more than $98 \mathrm{wt} . \%$ of REE using $2 \mathrm{M}$ sulfuric acid for the leaching of $\mathrm{Ni}-\mathrm{MH}$ at $90^{\circ} \mathrm{C}$ for $4 \mathrm{~h}$ at the solid to liquid ratio (S/L) of $1 / 20$. Sobianowska-Turek (2018) applied the one stage leaching with $3 \mathrm{M}$ sulfuric acid at temperature $25^{\circ} \mathrm{C}$ and at S/Lof 1:10. This process was very effective. The leaching efficiency of metals was the 
following: more than 97 wt. \% of $\mathrm{Ce}(\mathrm{III}), 88$ wt. \% of $\mathrm{La}(\mathrm{III}), 66$ wt. \% of $\mathrm{Ni}(\mathrm{II}), 79$ wt. \% of $\mathrm{Co}(\mathrm{II})$.

Separation of rare earth elements (REEs) from pregnant leach liquor (PLL) is very difficult. The similar physicochemical properties make their separation a huge challenge (Lister et al., 2014; Jha et al., 2016). On the other hand, this separation stage is necessary in the hydrometallurgical technology.

Solvent extraction (SX) is very often used as the industrially method of metal ions separation from technological aqueous solutions using the commercial extractants (Xie et al., 2014; Mishra et al., 2016; Kim et al., 2012).

Mechanism of solvent extraction of lanthanide ions by acidic extractants (cation exchangers) can be represented as follows(Xie et al., 2014):

$$
\mathrm{Ln}^{3+}{ }_{(\mathrm{aq})}+3 \mathrm{HA}_{(\mathrm{org})} \Leftrightarrow \mathrm{LnA}_{3(\mathrm{org})}+3 \mathrm{H}^{+}(\mathrm{aq})
$$

where:

Ln - denotes lanthanide ions,

HA - acidic extractant.

The acidic extractants, such as Cyanex 272 and D2EHPA are aggregated as dimmers. Thus the chemical equation is the following (Swain \& Otu, 2011; Xie et al., 2014):

where:

$$
\mathrm{Ln}^{3+}{ }_{(\mathrm{aq})}+3 \mathrm{H}_{2} \mathrm{~A}_{2(\mathrm{org})} \Leftrightarrow \operatorname{Ln}\left(\mathrm{HA}_{2}\right) 3(\mathrm{org})+3 \mathrm{H}^{+}(\mathrm{aq})
$$

$\mathrm{H}_{2} \mathrm{~A}_{2}$ - acidic extractant.

The solvent extraction of metal ions from various aqueous solutions after leaching of Ni-MH were studied by Li et al. (2009), Rodrigues \& Mansur (2010), Mishra \& Sahu (2016), Swain \& Out (2011), Kim et al. (2012), Fernandes et al. (2014), Zhao et al. (2017) and others. As can be seen from literature review (Xie et al., 2014; Jha et al., 2016) the separation processes require further improvement. The purpose of the present work was the selective extraction of $\mathrm{La}, \mathrm{Ce}, \mathrm{Ni}, \mathrm{Co}, \mathrm{Fe}, \mathrm{Mn}$ and $\mathrm{Zn}$ from leach liquor of the spent $\mathrm{Ni}-\mathrm{MH}$ using phosphorous compounds and ionic liquids (ILs).

\section{EXPERIMENTAL PART}

\section{Reagents}

Inorganicreagents, i.e. sulphuricacid $\left(\mathrm{H}_{2} \mathrm{SO}_{4}\right)$ was of analytical grade and was purchased from POCh (Gliwice, Poland).

Organicreagents, i.e. di(2-ethylhexyl) phosphoric acid (D2EHPA), bis (2,2,4trimethylpentyl) phosphinic acid (Cyanex 272), trihexyl (tetradecyl) phosphonium bis (2,4,4-trimethylpentyl) phosphinate (Cyphos IL 104) were of analytical reagent grade (Aldrich) and used without further purification.

\section{Leaching experimental}

$\mathrm{NiMH}$ rechargeable batteries are quite popular and widely used. Detailed description of their construction can be found elsewhere. In our research batteries of AA size of different manufacturers were used. All batteries were not dismantled and cut into 6-8 pieces and crushed into small parts below $5 \mathrm{~mm}$ and used for leaching experiments. 
In each test a sample of about $3.0 \mathrm{~g}$ of the crushed battery was leached in appropriate volume of chosen acid solutions of suitable concentrations in a thermostatic beaker under mechanical stirring at the rate of $600 \mathrm{rpm}$. Preliminary tests have shown that the stirring rates above $500 \mathrm{rpm}$ did not influence the rate of leaching. During and at the end of the experiments, samples of the pulp were taken and separated by filtration. The concentration of metal ions in the leach aqueous solutions was determined by atomic emission spectrometry method (spectrometer MP-AES 4200, made by Agilent).

\section{Solvent extraction}

Solvent extraction experiment was described in the previous paper (Pospiech, 2015). Equal volumes (each $10 \mathrm{~cm}^{3}$ ) of organic and aqueous phases were shaken for 10 minutes at $22 \pm 2^{\circ} \mathrm{C}$. Next, the phases were separated. The sample of the aqueous phase was taken in order to metals concentration determination by atomic emission spectrometry method.

Distribution ratio (D) and extraction efficiency (\%E) were defined as follows:

$$
\begin{aligned}
& D=\frac{[M]_{\text {org }}}{[M]_{a q}} \\
& \% E=\frac{D}{D+1} \cdot 100 \%
\end{aligned}
$$

where:

$[\mathrm{M}]_{\text {org }}$ and $[\mathrm{M}]_{\text {aq }}$ denote metal concentrations in the organic and aqueous phases after solvent extraction, respectively.

The metal concentration in the organic phase was deduced by mass balance.

Selectivity coefficient ( $\mathrm{S}_{\mathrm{M} 1 / \mathrm{M} 2)}$ ) for $\mathrm{M}_{1}$ over $\mathrm{M}_{2}$ was calculated as follows:

$$
\mathrm{S}_{\mathrm{M} 1 / \mathrm{M} 2}=\frac{D_{M 1}}{D_{M 2}}
$$

\section{RESULTS AND DISSCUSSION}

The solvent extraction of metal ions from acidic pregnant leach liquor (PLL) was carried out. Table 1 shows the composition of the aqueous solution used for the solvent extraction with $0.1 \mathrm{M}$ D2EHPA in kerosene.

Table 1 The composition of the aqueous solution used for the solven
\begin{tabular}{|c|c|}
\hline Metal & The concentration of metal, $\mathbf{g} / \mathbf{d m}^{\mathbf{3}}$ \\
\hline $\mathrm{Fe}$ & 1.57 \\
\hline $\mathrm{Ni}$ & 3.44 \\
\hline $\mathrm{Co}$ & 0.362 \\
\hline $\mathrm{La}$ & 0.538 \\
\hline $\mathrm{Ce}$ & 0.173 \\
\hline $\mathrm{Nd}$ & 0.024 \\
\hline $\mathrm{Pr}$ & 0.093 \\
\hline $\mathrm{Gd}$ & 0.133 \\
\hline $\mathrm{Zn}$ & 0.108 \\
\hline $\mathrm{Mn}$ & 0.146 \\
\hline $\mathrm{K}$ & 0.082 \\
\hline
\end{tabular}

As can be seen, the aqueous phase contained very high concentration of $\mathrm{Ni}(\mathrm{III})$ and $\mathrm{Fe}(\mathrm{III})$. Presence of $\mathrm{Fe}(\mathrm{III})$ in leach liquors is serious technical problem 
because this metal is impurity requiring removal. The previous studies showed that organophosphorus extractants allow for removal of $\mathrm{Fe}$ (III) from aqueous solutions (Pospiech \& Walkowiak, 2005, 2010). D2EHPA is the one of the most popular cationic extractants. This reagent was used for the selective extraction of iron(III) from the studied aqueous solution.

The results of the metals extraction are shown in Fig. 1. As can be seen, the highest extraction efficiencies were obtained for $\mathrm{Fe}(\mathrm{III}), \mathrm{Zn}(\mathrm{II}), \mathrm{Mn}(\mathrm{II})$ and $\mathrm{K}(\mathrm{I})$ and were $99.4 \%, 99.2 \%, 97.8 \%$ and $95.4 \%$, respectively. The mentioned metals extracted from the aqueous solution at low $\mathrm{pH}$ of 0.1 . The conditions are not suitable for extraction REE and $\mathrm{Ni}(\mathrm{II})$ and $\mathrm{Co}(\mathrm{II})$. The extraction percent of these metals was below $5 \%$.

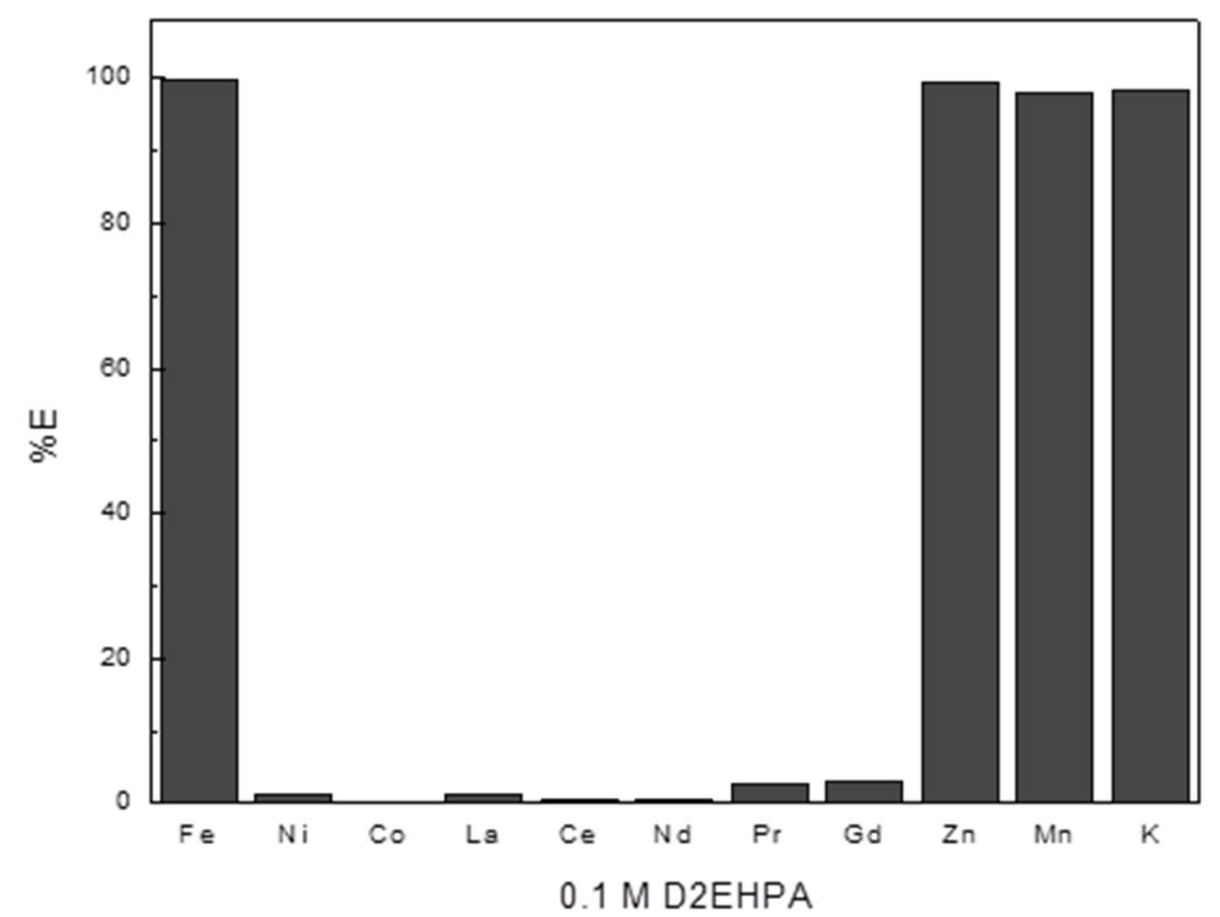

Fig. 1 Extraction efficiency (\%) of metal ions from acidic pregnant leach liquor (PLL) with $0.1 \mathrm{M}$ D2EHPA in kerosene (phase volume ratio $\mathrm{O} / \mathrm{A}=1$ )

Thus, this solvent extraction process was very selective and allowed for the selective extraction of the metals group, such as $\mathrm{Fe}(\mathrm{III}), \mathrm{Zn}(\mathrm{II}), \mathrm{Mn}(\mathrm{II})$ and $\mathrm{K}(\mathrm{I})$. Fig. 2 shows the selectivity of process (logS) for Fe(III) over Ni(II), Co(II), La(III), $\mathrm{Ce}(\mathrm{III}) \mathrm{Nd}(\mathrm{III}), \operatorname{Pr}(\mathrm{III}), \mathrm{Gd}(\mathrm{III})$ as well as $\mathrm{Zn}(\mathrm{II}), \mathrm{Mn}(\mathrm{II})$ and $\mathrm{K}(\mathrm{I})$. As can be observed, the highest selectivity was obtained for Fe(III) over $\mathrm{Co}$ (II) and REE. In the next stage, REE were extracted with the mixture of $0.1 \mathrm{M}$ Cyanex 272 and $0.1 \mathrm{M}$ Cyphos IL 104 at $\mathrm{pH}$ equal to 3.8. The mixture of the selected extractants are very often better extractant than the single compounds. As can be seen from Fig. 3, REEs have been selective removed from the aqueous phase. In this case, the application of the mixture of organophosphorus extractant (Cyanex 272) and the ionic liquid (Cyphos IL 104) gave beneficial effects. Ni(II) and Co(II) remained in the aqueous phase. The main aim of the next investigations was the selective extraction of $\mathrm{Ni}(\mathrm{II})$ and $\mathrm{Co}(\mathrm{II})$ from the aqueous solution. 


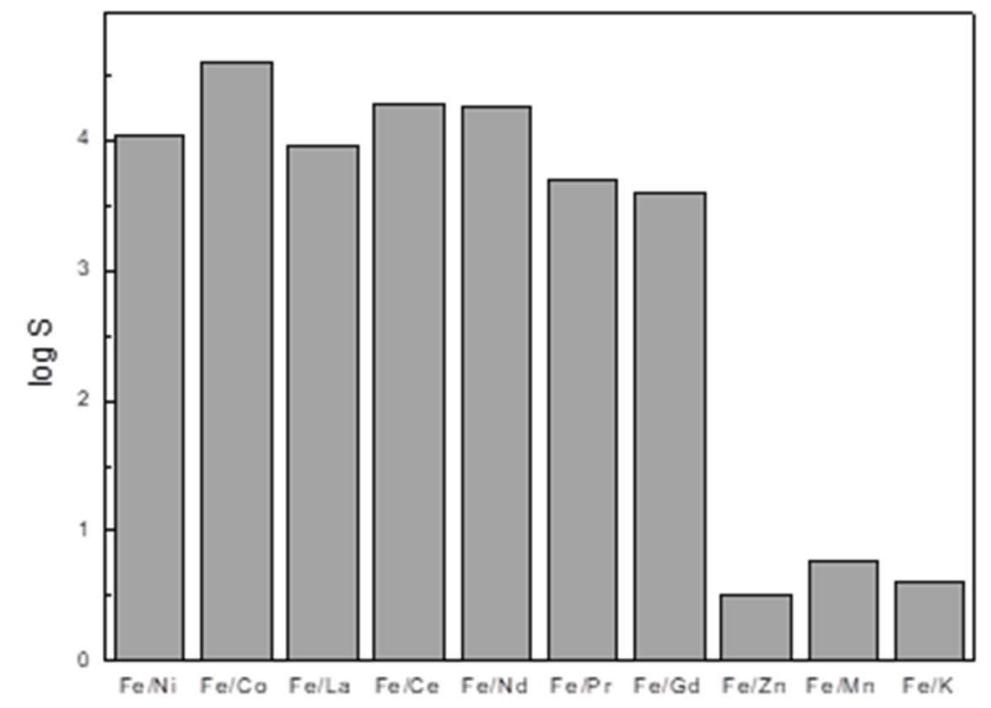

Fig. 2 Selectivity extraction of $\mathrm{Fe}(\mathrm{III})$ over others metal ion from acidic pregnant leach liquor (PLL) with 0.1 M D2EHPA in kerosene (phase volume ratio O/A=1)

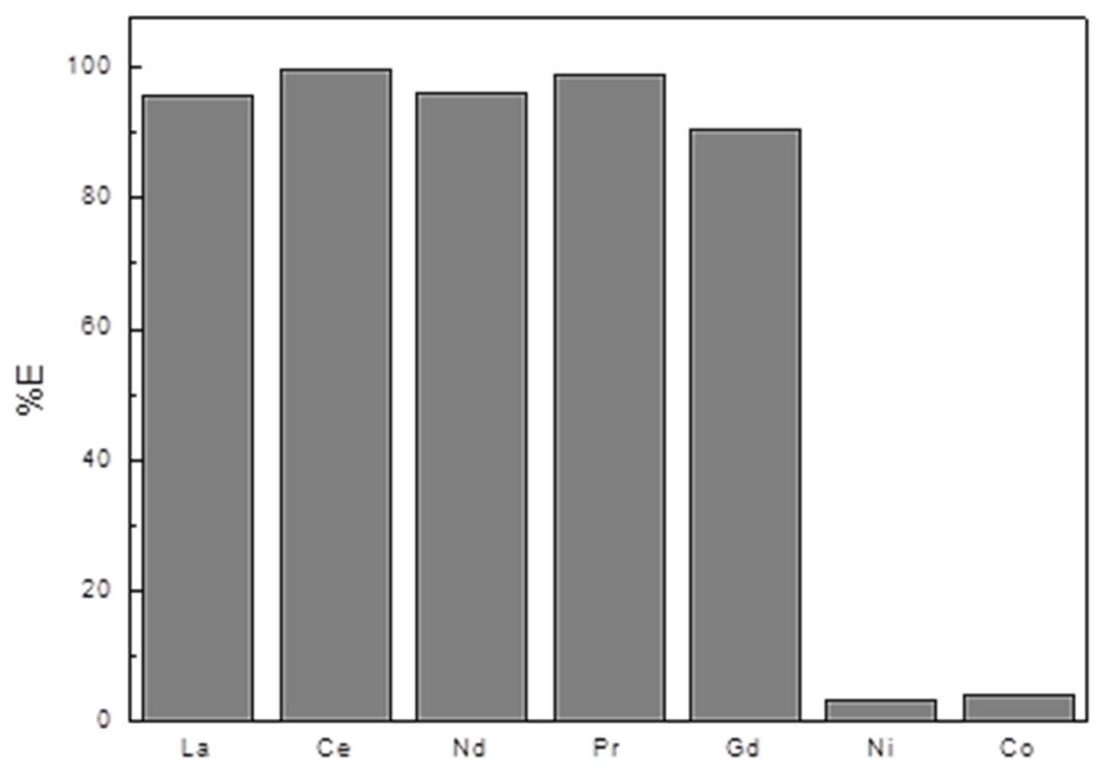

Mixture of $0.1 \mathrm{M}$ Cyanex 272 and $0.1 \mathrm{M}$ Cyphos IL 104

Fig. 3 Extraction efficiency (\%) of metal ions from acidic pregnant leach liquor (PLL) with $0.1 \mathrm{M}$ Cyanex 272 and Cyphos IL 104 in toluene at $\mathrm{pH}=3.8$ (phase volume ratio $0 / \mathrm{A}=1$ )

The studied metals show similar physicochemical properties in the aqueous solutions and their separation is difficult (Gega et al., 2001). Recently, as can be seen from review of literature, the ionic liquids (ILs) are very often used for extraction of metal ions (Pospiech \& Kujawski, 2015). Cyphos IL 104 was selected for the extraction of $\mathrm{Ni}(\mathrm{II})$ and $\mathrm{Co}(\mathrm{II})$ among many ILs due to the fact that it is an ecologic reagent and commercially available. Fig. 4 shows the extraction efficiency (\%) of $\mathrm{Ni}(\mathrm{II})$ and $\mathrm{Co}(\mathrm{II})$ in depending on $\mathrm{pH}$ of the aqueous phase with $0.1 \mathrm{M}$ Cyphos IL 104 in toluene. As can be observed, Co(II) was better extracted from the solution and the extraction efficiency increased from $30 \%$ at $\mathrm{pH}$ of 3.8 to $96 \%$ at $\mathrm{pH}=5.4 \mathrm{Ni}(\mathrm{II})$ was poorly extracted from the studied solution and the extraction percent increased from $12 \%$ at $\mathrm{pH}$ of 3.8 to $18 \%$ at $\mathrm{pH}$ of 5.4 . 


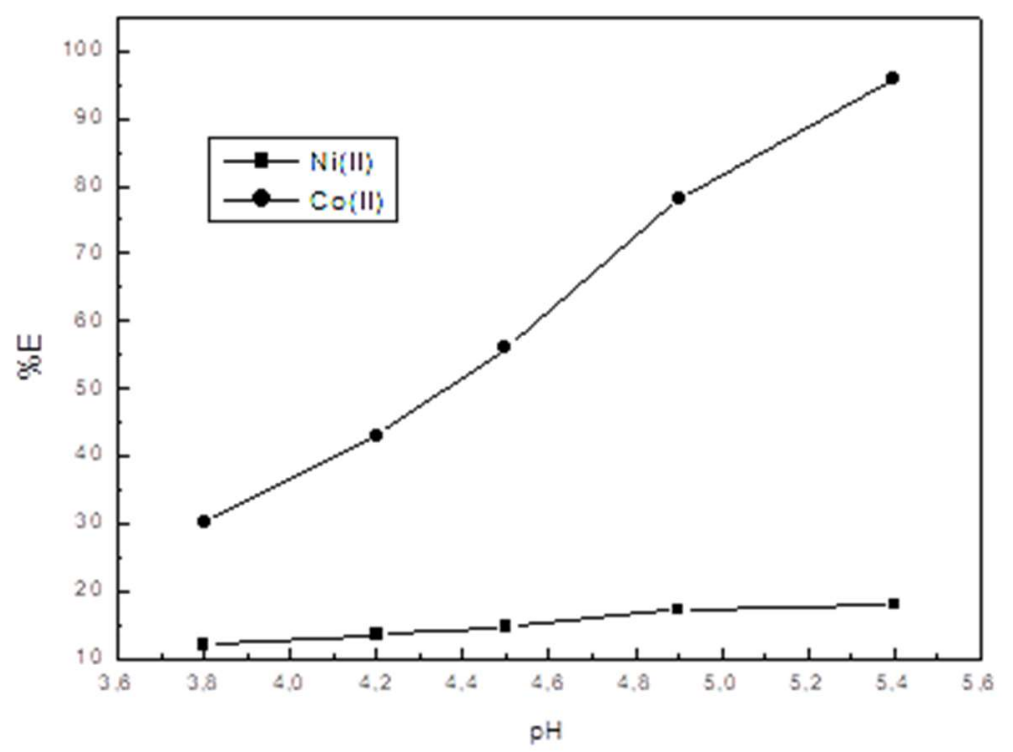

Fig. 4 Extraction efficiency (\%) of $\mathrm{Ni}$ (II) and $\mathrm{Co}$ (II) in depending on $\mathrm{pH}$ of the aqueous solution with $0.1 \mathrm{M}$ Cyphos IL 104 in toluene at $\mathrm{pH}=5.4$ (phase volume ratio $\mathrm{O} / \mathrm{A}=1$ )

Fig. 5 demonstrates the selectivity of this extraction process for $\mathrm{Co}(\mathrm{II})$ over $\mathrm{Ni}(\mathrm{II})$. The selectivity increased with the increasing $\mathrm{pH}$ of the aqueous solution. As can be observed, the optimal $\mathrm{pH}$ for the selective extraction of this pair of metals with Cyphos IL 104 was 5.4 .

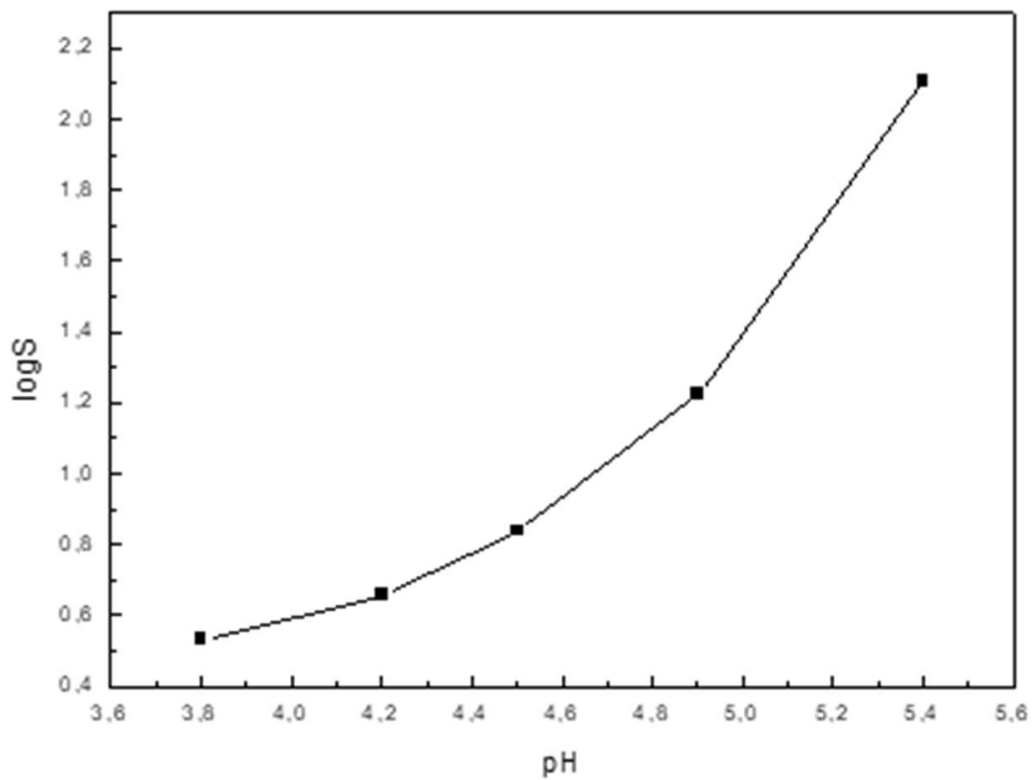

Fig. 5 Selectivity extraction of $\mathrm{Co}(\mathrm{II})$ over $\mathrm{Ni}(\mathrm{II})\left(\log \mathrm{S}_{\mathrm{Co} / \mathrm{Ni}}\right)$ from the aqueous solution with $0.1 \mathrm{M}$ Cyphos II 104 in toluene (phase volume ratio O/A=1)

\section{CONCLUSION}

The results presented in this work shows that the solvent extraction can be used for the selective recovery of the useful metals from leach liquor of the spent $\mathrm{Ni}$ $\mathrm{MH}$ batteries. 0.1 M D2EHPA can be used for the selective removal of $\mathrm{Fe}(\mathrm{III})$, $\mathrm{Zn}(\mathrm{II}), \mathrm{Mn}(\mathrm{II})$ and $\mathrm{K}(\mathrm{I})$ from PLL. REEs were extracted using the mixture of 0.1 M Cyanex 272 and $0.1 \mathrm{M}$ Cyphos IL 104. In the last stage of this process, $\mathrm{Ni}$ (II) and $\mathrm{Co}(\mathrm{II})$ ions were selective extracted from the aqueous solution with $0.1 \mathrm{M}$ 
Cyphos IL 104. This extractant appears the suitable extractant for separation of $\mathrm{Ni}(\mathrm{II})$ and $\mathrm{Co}(\mathrm{II})$ from aqueous sulfate solutions.

The most important from the practical point of view is the fact that the spent $\mathrm{Ni}$ $\mathrm{MH}$ batteries can be the source of valuable metals such as REEs. Application of the solvent extraction with the selected extractants under appropriate conditions allows for the selective extraction of metal ions. Futher studies are necessary to recover pure metals or their compounds from aqueous solutions.

\section{ACKNOWLEDGEMENTS}

The research was supported by the BS/PB-207-301/09.

\section{REFERENCES}

Bertuol, D.A., Bernardes, A.M., Tenorio, J.A.S. (2009). Spent NiMH batteries - The role of selective precipitation in the recovery of valuable metals. Journal of Power Sources, 193, pp. 914-923.

Chagnes, A., Pospiech, B. (2013). A Brief Review On Hydrometallurgical Technologies For Recycling Spent Lithium-Ion Batteries. Journal of Chemical Technology and Biotechnology,88,pp. 1191-1199.

Fernandes, A., Afonso, J.C., Dutra, A.J.B. (2013). Separation of Nickel(II), Cobalt(II) and Lanthanides from Spent Ni-MH Batteries by Hydrochloric Acid Leaching, Solvent Extraction and Precipitation. Hydrometallurgy 133, pp. 37-43.

Gega, J., Gajda, B., Walkowiak, W. (2001). Separation of Co(II) and Ni(II) ions by Supported and Hybrid Liquid Membranes, Separation and Purification Technology, 22-23, pp. 551-558.

Innocenzi, V., Ippolito, N.M., De Michelis, I., Prisciandaro, M. (2017). A Review Of The Processes and Lab-Scale Techniques For The Treatment Of Spent Rechargeable NimhBatteries. Journal of Power Sources, 362, pp. 202-218.

Jha, M.K.; Kumari A.; Pand, R.; Kumar, J.R.; Yoo, K.; Lee, J.Y. (2016).Review On Hydrometallurgical Recovery Of Rare Earth Metals. Hydrometallurgy, 165, pp. 226.

Kim, J.S., Kumar, B.N., Lee, J.Y., Kantam, M.L., Reddy, B.R. (2012). Separation and Recovery of Light Rare-Earths from Chloride Solutions using Organophosphorous based Extractants. Separation and Purification Technology, 47, pp. 1644-1650.

Li, L., Xu, S., Wu, Z.J. (2009). Recovery of Ni, Co and Rare Earths from Spent Ni-Metal Hydride Batteries and Preparation of Spherical $\mathrm{Ni}(\mathrm{OH})_{2}$. Hydrometallurgy, 100, pp. 41-46.

Lister, T.E.; Wang, P.; Anderko, A. (2014). Recovery of Critical And Value Metals from Mobile Electronics Enabled by Electrochemical Processing. Hydrometallurgy, 149, pp. 228-237.

Mishra, S.; Sahu, S.K. (2016). Solvent Extraction of Ce(III) from Nitric Acid Medium Using Binary Mixture of PC 88A and Cyanex921. Hydrometallurgy, 166, pp. 252259.

Meshram, P., Pandey, B.D., Mankhand, T.R. (2016). Process Optimization and Kinetics for Leaching of Rare Earth Metals from the Spent Ni-Metal Hydride Batteries. Waste Management, 51, pp. 196-203.

Meshram,P., Somani, H., Pandey, B.D., Mankhand, T.R., Daveci, H., Abhilash (2017). Two Stage Leaching Process for Selective Metal Extraction from Spent Nickel Metal Hydride Batteries. Journal of Cleaner Production, 157, pp. 322-332.

Pospiech, B., Walkowiak, W. (2005). Application of TBP in Selective Removal of Iron(III) in Solvent Extraction and Transport Through Polymer Inclusion Membranes Processes. Physicochemical Problems of Mineral Processing, 39, pp. 89-98.

Pospiech, B., Walkowiak, W. (2010). Studies on Iron(III) Removal from Chloride Aqueous Solutions by Solvent Extraction and Transport Through Polymer Inclusion 
Membranes with D2EHPA. Physicochemical Problems of Mineral Processing, 44, pp. 195-204.

Pospiech, B. (2013). Hydrometallurgical Recovery of Cobalt(II) from Acidic Chloride SI. olutions by Transport Through Polymer Inclusion Membranes. Physicochemical Problems of Mineral Processing, 49, pp. 641-649.

Pospiech, B. (2015). Studies On Extraction and Permeation of Cadmium(II) using Cyphos IL 104 as Selective Extractant and Ion Carrier. Hydrometallurgy, 154, pp. 88-94.

Pospiech, B., Kujawski, W. (2015). Ionic Liquids as Selective Extractants and lon Carriers of Heavy Metal lons from Aqueous Solutions Utilized in Extraction and Membrane Separation. Review and Chemical Engineering, 31, pp. 179-191.

Rodrigues, L.E., Mansur, M.B.(2010). Hydrometallurgical Separation of Rare Earth Elements, Cobalt and Nickel from Spent Nickel-Metal-Hydride Batteries. Journal of Power Sources, 195, pp. 3735-3741.

Sobianowska-Turek, A. (2018). Hydrometallurgical Recovery of Metals: Ce, La, Co, Fe, $\mathrm{Mn}, \mathrm{Ni}$ and $\mathrm{Zn}$ from the Stream of used Ni-MH Cells. Waste Management, 77, pp. 213-219.

Swain, B.; Otu, E.O. (2011). Competitive Extraction of Lanthanides by Solvent Extraction using Cyanex 272: Analysis, Classification and Mechanism. Separation and Purification Technology, 83, pp. 82-90.

Xie, F.; Zhang, T.A.; Dreisinger, D.; Doyle, F. (2014). A Critical Review on Solvent Extraction of Rare Earths from Aqueous Solutions. Minerals Engineering, 56, pp. 10-28.

Zhang, P., Yokoyama, T., Itabashi, O., Wakui, Y., Suzuki, T.M., Inoue, K. (1998). Hydrometallurgical Process for Recovery of Metal Values from Spent Nickel-Metal Hydride Secondary Batteries. Hydrometallurgy, 50, pp. 61-75.

Zhao, Z.; Qiu, Z.; Yang, J.; Lu, S.; Cao, L.; Zhang, W.; Xu, Y. (2017). Recovery of Rare Earth Elements From Spent Fluid Catalytic Cracking Catalysts using Leaching and Solvent Extraction Techniques. Hydrometallurgy, 167, pp. 183-188.

\begin{abstract}
.
The nickel metal hydride batteries (Ni-MH) are used in many electronic equipment, like cell phones, computers, cameras as well as hybrid cars. Spent batteries can be a rich source of many metals, especially rare earth elements (REE), such as lanthanum (La), cerium (Ce), neodymium (Nd), praseodymium ( $\mathrm{Pr}$ ), samarium ( $\mathrm{Sm})$, gadolinium ( $\mathrm{Gd})$. Ni-MH batteries also contain iron ( $\mathrm{Fe})$ as well as non-ferrous metals, i.e. nickel $(\mathrm{Ni})$, cobalt $(\mathrm{Co})$, zinc $(\mathrm{Zn})$, manganese (Mn), etc. Leaching of such waste with sulfuric acid solutions is one among many methods recovering of useful metals in hydrometallurgical processes. The main aim of this work was separation of metal ions from pregnant leach liquor (PLL) by solvent extraction using phosphorous compounds and ionic liquids (ILs). The initial $\mathrm{pH}$ of the aqueous solution was 0.1 . Di (2-ethylhexyl) phosphoric acid (D2EHPA), bis (2,2,4-trimethylpentyl) phosphinic acid (Cyanex 272), and phosphoniumionic liquid - trihexyl (tetradecyl) phosphonium bis $(2,4,4-$ trimethylpentyl) phosphinate (Cyphos IL 104) were used as the selective extractants. The initial concentration of the extractants in an organic phase was equal to $0.1 \mathrm{~mol} \cdot \mathrm{dm}^{-3}$. The obtained results show that the highest extraction efficiency was obtained for $\mathrm{Fe}$ (III) and $\mathrm{Zn}$ (II) in extraction experiments with $0.1 \mathrm{M}$ D2EHPA at $\mathrm{pH}$ of 0.1 . Ni(II), Co(II) and REE remained in the aqueous solutions. In the next stage, REE were extracted with the mixture of $0.1 \mathrm{M}$ Cyanex 272 and $0.1 \mathrm{M}$ Cyphos IL 104 at pH equal to 3.8. Finally, Ni(II) and Co(II) ions were efficiently removed from the aqueous phase using $0.1 \mathrm{M}$ solution of Cyphos IL 104 at pH around 5.4 .
\end{abstract}

Keywords: solvent extraction, rare earth metals, nickel metal hydride batteries 